\title{
Gender Differences on Cognitive and Affective Responses Within Tanzanian Physical Education Context Achievement Goal Approach
}

\author{
Cyprian Ngilisho Maro \\ Physical Education and Sport Sciences Department, University of Dares Salaam, Dares Salaam, Tanzania
}

Email address:

cyprianmaro@yahoo.com

\section{To cite this article:}

Cyprian Ngilisho Maro. Gender Differences on Cognitive and Affective Responses Within Tanzanian Physical Education Context Achievement Goal Approach. International Journal of Sports Science and Physical Education. Vol. 3, No. 2, 2018, pp. 16-26. doi: $10.11648 /$ j.ijsspe.20180302.11

Received: February 14, 2018; Accepted: March 14, 2018; Published: July 18, 2018

\begin{abstract}
This paper examined gender differences in cognitive and affective outcomes of participation in PE in secondary schools in Tanzania. The study adopted achievement goal approach and involved 400 PE students $($ male $=221$ : female $=179$ : $\mathrm{M}=17.21$ years, SD 1.69). A standardized questionnaires assessing goal orientation, purpose of PE, satisfaction and enjoyment in PE were utilized. Results confirmed the psychometric suitability of the research instruments when used in Kiswahili language. Furthermore, the multivariate analysis of variance indicated that there were significant gender differences between males and females in goal orientations and cognitive outcomes of participating in PE. Follow up univariate analyses indicated that males were higher in goal orientation, and believed that social status and enhanced lifetime health skills were important purpose of participation in PEthan females. On the other hand, females perceived social responsibility to be more important purpose of participating in PE than males. However, during participation in PE there were no gender differences in affective outcomes of satisfaction and enjoyment. Further analysisindicated that the goal orientation profiles of the individualinfluenced the outcome of participation in PE. The findings leads to a conclusion indicating that for Tanzanian PE students, gender differences have substantial influence on individual's responses in PE. Gender was found to influence the socialization process in terms of achievement goal orientation. It is recommended that PE teachers should enhance task to fosterpro-social behavior. As more and more women are engaging in nontraditional sport such as soccer, rugby, boxing, taekwondo and weight lifting future study should examine the effect of this trend in terms of gender differences in PE and sport.
\end{abstract}

Keywords: Gender, Achievement Goals, Physical Education, Psychological Outcome, Tanzania

\section{Introduction}

\section{Physical Education in schools in Tanzania.}

Physical Education (PE) programs in primary and secondary schoolsin Tanzania are over -two decade sold introduced in the late 1990s [1-4]. In secondary schools the subject is known as Physical Education and Sports. Because Kiswahili language is the language of instruction in primary schools, the PE subject is commonly known as "Haiba na Michezo"which translates to Personality Development and Sport (PDS) in English language. There are syllabuses and curricula for the two subjects for both primary and secondary schools [5]. Reportsand current studies indicate thatthe "Haiba na Michezo" is compulsory subject in primary schools and the Physical Education and Sport is an optional subjectin secondary schools and the subjects are currently being implemented [2, 5-10].

Thus, these two subjects are among other subjects that occupy the day-to day time table for the primary and secondary schools in Tanzania. However, the implementation has not been successful as expected. Studies indicate that PE does not hold a very strong position against other core subjects such as natural and social sciences, mathematics, or languages. AsPE subject in secondary schools is an option it is oftenplaced at late Friday afternoon hoursand first to be replacedby other subjects or been cancelledwhen national, regional and midterm examinations approaches. Likewise, in primary schools though is compulsory subject often the PE 
classes are informally replaced by special classes for the "prestigious" subjects such as mathematics and sciences for preparation for examinations [7, 9-13]. Generally, there is evidence also that that PE often suffers when it comes to resource distribution [14].

In Tanzania between 2001 and 2010 PE in primary and secondary schools has suffered due to political oversight and was suspended for period of timeby the then government minister responsible for education sector before being reintroduced again [13, 15]. Nevertheless, PE teachers and educators areconstantly fostering greater understanding ofphysical education so that it isequally recognized and made compulsory in secondary schools as other traditional core subjects $[3,7,8,11,13,16$, ]. Examining the implementation of PE in secondary schools and in particular examining the cognitive and affective outcome of participation in $\mathrm{PE}$ programs is one such effort. It is clearly recognized thatinteraction of students with the physical education and sports instructional content, materials, resources and processes at schools occur within socio-cultural context. Thus, the present study examinesthe psychological outcomes of participation in PE as they are influenced by the culturally based gender stereotypes existing in Tanzanian society [11, $16,17]$.

\section{Gender differences in $P E$}

Given the fact that African societies are culturally based [18] and both boys and girls participate in PE classes at different intensity and settings [16], it is beneficial to understand the gender differences in PE in Tanzania. Studiesindicated that there are wide differences amongand between teachers and students [11, 19-23]. There is also evidence that boys and girls differ in their task specific expectancies for sex-types PE and sport activities [see 2427]. Amongaspect in PE where gender differences often manifest are the cognitive and affective outcomes such as purpose of PE, satisfaction and enjoyment. The PE students in secondary schools are thus examined to understand thegender differences in the cognitive and affective outcome of participation in PE within Tanzanian context. However, understanding of these psychological outcome variables of participation requires a theoretical perspective that is culturally sensitive. For over six decades researchers have used theories of motivation in particular expectancy value, [28], self efficacy [29], and goal orientation [30, 31] to understand and explain differences in motivation of individuals in PE and sport context.

\section{Motivational Perspective}

Motivation is known to be very useful in understanding why people become involved in achievement activities such as physical education [32]. In the PE context, motivation refers to dispositions, social variables, and/or cognitions that manifest when a person participate in evaluative tasks such as $\mathrm{PE}$ or enter into a competition with others or attempt to attain some standards of excellence [e.g., 32]. Over the years, motivation research in $\mathrm{PE}$ and sport hasbeen dominated by two major theoretical approaches namely self-determination theory $[33,34]$ and achievement goal theory $[30,32]$. The achievement goal theoryconsiders that individual's goal perspective in a particular setting to befunction of dispositional (personal goal orientations) and situational factors (motivational climate) [35]. The present study adopts the achievement goal theory and in particular the goal orientations in examining gender differences in cognitive and affective responses within PE context in an African culture.

Research has found that, goal orientations of the individual are meaningfully related to the individual's belief concerning the wider purpose of achievement activity [13, 19, 30, 36, ]. Previous study in Tanzanian PE contexthas indicated that the goals orientation of the PE students influences the outcomes of participation in PE programs [13]. Thus, the present research extend further the use of the goal theory byexaminingthe gender differences in the cognitive and affective outcomes (purpose of PE, satisfaction and enjoyment)of participation in PE programs in secondary schools in Tanzania using the achievement goal approach(see [30, 31, 37].

Goal orientations. Much of the research on motivational perspectives has underscored the relevance of goal perspectives to our understanding of behavior in achievement situations like in physical education and in sport [35, 38]. Research based in social cognitive perspective and focusing on the goal achievement has revealed that two major goals orientations (task and ego goal) take place in achievement situations and the goal of the individual is demonstration of ability. Thus, the two goal orientation (task and ego) are underpinned by two conceptions of ability, namely undifferentiated and differentiated conceptions of ability [30, 39].

A person can conceptualize ability as effort and thisreflect undifferentiated conception of ability. In this case ability is not differentiated from effort and means trying hard, learning and understanding something more comprehensively. This conceptualization of ability is associated with task orientation [40] and individual will define success interms ofselfimprovement, putting effort, cooperation, learning from mistakes and master of the task.

On the other hand, a person can differentiate ability from effort and is conceptualized as capacity. When this happens, itlimits what effort can accomplish and this is associated with ego orientation [40] and individual will define success in terms of outperforming others (preferable with little effort) and showing relative ability than others. Therefore, when individual believes that ability or competence is demonstrated when mastery and learning are achieved and high effort exerted, task state of involvement exist. However, when individual believes that ability or competence is demonstrated when more is achieved with less effort than others, ego stage of involvement exist $[30,32]$. Therefore, the two orientations (task and ego) reflect the criteria individuals use to subjectively define success and failure in achievement situations [30, 41].

Together with reflecting personal criteria for success, individuals personal achievement goals (i.e., being task and/or ego oriented) are assumed to be linked to their world 
views about purpose of education [42], of sport [36, $43,44]$ and of physical education $[13,45-48]$ in a conceptually coherent fashion.

\section{Goal orientation and cognitive outcomes}

Specifically, task orientation has been linked to the purpose of PE as to promote mastery, cooperation, social responsibility, life skills learning and pro-social behaviors $[13,49]$. In other areas like in education and in sport similar association with goal orientation has been found. For example, in education, task orientation has been associated with the belief that education is an end in itself meaning that individual should be socially committed, having commitment to learning, understanding and mastering educational materials. Likewise in sport task orientation has been linked to view that sport should foster honesty and respect, enhance one's self esteem, teach people to try their best, cooperate and be good citizens [32].

On the other hand, ego orientation has been linked to view that purpose of PE was to enhance one's social status [49, 13]. In sport, ego orientation was linked to view that sport should enhance one's self esteem and social status [44]. Likewise in educationego orientation has been associated with the view that education is the means to another end such as high socio-economic status and wealth. For students these include obtaining higher grades, show superiority among peers, admission to higher-level school with respected status.

\section{Goal orientation and affective outcomes}

Satisfaction: Research in PE and sport using achievement goal theory has consistently indicated that there is link between task orientation and satisfaction during participation in physical activity [50]. Lochbaum and Roberts [51]. while examining the relationship between athlete's goal orientations and feeling of satisfaction found that task oriented athletes felt more satisfied than ego oriented ones. However, the ego oriented athletes were also found to be satisfied. In this research it was further found that the task oriented athletes derived their satisfaction from personal references while the ego oriented athletes derived their satisfaction from normative ability. Furthermore, study by Roberts and Ommundsen [52]indicated that task oriented students were satisfied with learning and personal improvement whereas ego oriented students were satisfied with superior ability than others.

The literature therefore, highlights the importance of maintaining task orientation for more satisfaction as there is a link or interdependence between individual's goal orientation and the satisfaction one experiences while participating in physical activity. Therefore, task orientation should generate greater satisfaction in physical activity because competence is judged in terms of mastery and effort concepts that are within the individual. On the other hand, ego orientationis supposed to lead to decrease in satisfaction particularly with low ability $[53,30]$ because competence is judged in terms of social comparison elements.

Enjoyment: Research indicate enjoyment as one of the major constructs for understanding and explaining experiences and motivation of people who participate in physical activity [54]. Enjoyment is a multidimensional construct most often used to indicate intrinsic motivation [55] but it is broader and inclusive consisting of dimension related to affect, excitement, perception of competence, attitude and cognitions [56]. In fact, there is one famous quote that " sports comprise one of the most pervasive sets of activities that people engage in for enjoyment' [57] p.389). Enjoyment can be derived from intrinsic sources (e.g., autonomous, achievement and movement/sensory experience) and extrinsic sources (e.g., social achievement, social recognition and interpersonal relationships, extrinsic rewards such as trophies). This study consider the concept of enjoyment from intrinsic motivation approach in which it has a role of generating motivation and where enjoyment is operationally defined as

"positive affective responses to a particular sport activity that reflects generalized feelings described in terms such as enjoy, happy, like and fun" [53], p.11).

Although enjoyment in many cases has been used to represent intrinsic motivation, activities which are not intrinsically motivating may be equally enjoyable to participants [55]. Limited research has examined enjoyment in school physical education but research in sport has yielded consistent evidence of its importance in motivational consequences. For example, studies done using children and adolescents in school programs have indicated that the major reason for participating in a program is the desire for enjoyment or fun, while dropping out has been caused by lack of enjoyment (e.g., [58].

There are consistent findings showing association between task orientation and experienced enjoyment during participation in physical activity. For example, in one study using high school students [59] and in another study using athletes competing in regional competitions, summer sport camp and participants from variety of physical activity classes $[60,61]$ the relationship between task orientation and enjoyment was found. Similarly, positive relationship between task orientation and flow as enjoyable experiencewas reported when examining athletes [62]. However in this study, similar relationship was found with ego oriented athletes with high perception of ability while, athletes with low perception of ability experienced enjoyment less frequently during competition.

As goals orientationsare meaningfully related to cognitive, and affective outcome of participation in physical activity $[49,36]$ and as boys and girls differ in their task specific expectancies for sex-types PE and sport activities, [e.g., 24]it is worthwhile to examine gender differences in cognitive and affective outcomes of participation in PE.

Although it is evident that masculinity and femininity have multiple meanings that are socially constructed[63], and there is evidence that sex stereotype influence beliefs about competence, limitedresearch has assessed differences in cognitive and affective outcome of participation in physical activity such as PE [e.g., 13, 47, 20]. There are great numbers of descriptive studies within Tanzanian context [3, 16, 13], however limited studies have examined cognitive and 
affective outcomes of participation in PE. Therefore, the present study examined the gender differences in cognitive and affective outcomes of participation in PE within the achievement goal approach.

\section{Methods}

\subsection{Participants and Procedure}

Physical education students in secondary education in Tanzania participated in the present study. The schools that offered PE lessons were purposively selected and a sample was randomly selected from each of these schools. The total sample for the present study were 400 PE studentscomprising of 221 males, and 179 femalesstudents aged between 14-23 years participating in PE classes during the study $(\mathrm{M}=17.21$ years, SD 1.69. The students in this research were in their second year of four-year program of secondary education. There is evidence that PE students enrolled in PE programs and who are older than 14 years would have accumulated enough experience in PE and sport activities toreflect their perceptions, attitudes and behavior towards PE and sport [64]. The students responded to a questionnaire in group settings during PE classes after an informed consent was obtained.

\subsection{The Research Instruments}

To obtain information from PE students, a questionnaire was used. The questionnaire comprised of scales assessing goal orientation, purpose of PE, satisfaction and enjoyment.

\subsubsection{Goal Orientation}

A Perception of Success Questionnaire (POSQ) was used to assess goal orientation of the individual namely task and ego orientation. This instrumentPOSQ has been developedand been used in American and European adolescents [65] but it has also being found both reliable and valid with PE students in Tanzania context in previous studies [13]. The students completed the 12 items POSQ scale and were requested to think of when they felt most successful in PE classes. The 12 items, 6 reflected task and 6 reflected ego referenced criteria of success and their responses indicated in a 5-point Likert scale $(1=$ strongly disagree, 5 = strongly agree).

\subsubsection{The Purpose of Physical Education Questionnaire}

The purpose of physical education questionnaire which was developed based on studies by [43, 44, 66] and, [52], and been previously used successfully within Tanzanian PE context [13]was used in this study. Using a 5-point Likert scale ( strongly disagree $=1$, strongly agree $=5$ ) the scale was used to asses perceived purpose of physical education.

\subsubsection{Satisfaction Scale}

The five items from satisfaction with sport scale [44] were modified to assess the satisfaction with PE. In the previous study, the five items reflected one factor and showed acceptable internal consistency. In the present study, PE students in secondary schools in Tanzania responded to the items reflecting general like and dislike for the PE experience. Each item was assessed using a 5-point Likert scale ranging from strongly agree (5) to strongly disagree (1).

\subsubsection{Enjoyment Scale}

A four item enjoyment scale was modified and used to analyze enjoyment in PE participation. This scale had been successfully used in previous studies assessing enjoyment in training and in game situations $[67,53]$. In the present study each item was rated on 5-point Likert scale ranging from strongly agree (5) to strongly disagree (1)

Furthermore student indicated their age and gender by filling their age in years at the time of the study and their gender as either male or female. The whole instrument was originally written in English language and underwent extensive process of double translation back-translation to Kiswahili language. Kiswahili language is a national and widely spoken language in Tanzania. Although English is a language of instruction in secondary schools, majority of students interact in Kiswahili during classes and outside classes. Thus, it was deemed effective to let the students respond in the Kiswahili language which they have greater command in.

\section{Results}

\subsection{Psychometric Analysis of the Research Instruments}

\subsubsection{Perception of Success Questionnaire (POSQ)}

Because the instrument was also used in cross-cultural context, factor analyses (Principal components with both varimax and oblique rotations with number of factors not specified) were conducted. The results of the principal components analysis of the POSQ items yielded two factors with six items each reflecting a task goal and ego goal perspectives respectively. The two factors were acceptedas each was observed to have eigenvalues $>1$, a variance $>5 \%$ and a factor weightbetter than 0.50 andhad satisfactory reliabilities ( $\alpha=.68$ and $\alpha=.76$ respectively). Furthermore, the orthogonal rotationwas acceptable as the interrelations between the task items and ego items were low ( $\mathrm{r}=$ 0.14)which confirmed the stability of the task and ego subscales [70]. Therefore, the two scales were successfully used for further analysis to measure the goal orientations of the PE students in the present study.

\subsubsection{Purpose of PE Questionnaire}

Purpose of PE questionnaire consisted of 13 items and was used to assess perceived purpose of Physical Education. A factor analysis was conducted on the questionnaire including orthogonal and oblique rotations and produced three factors with eigenvalues $>1$ and acceptable variance $(56.1 \%)$. The first factor comprised of 5 items reflecting belief that participation in PE enhance one's social status (variance $30.2 \%$ ). The second subscale (accounting for $15.8 \%$ of variance) consisted of 5 items focusing on social responsibility related reasons for participation. The last factor 
(accounting for $10.0 \%$ of variance) comprised of three items reflecting the belief that participation in physical education contributes to development of lifetime health skills. Thus, the scales produced similar structure with the sample and thus were used in the further analyses in the present study.

\subsubsection{Satisfaction and Enjoyment Scales}

The five items of the satisfaction scale formed one factor (eigenvalues $=2.3$, variance $=46.0 \%$ ) scale with acceptable internal consistency $(\alpha=.69)$. The enjoyment scale which consisted of four items had acceptable internal consistency ( $\alpha$ increased to.66) after one item ("I had fun in PE") was deleted. The lowest correlation was found between the "fun"item and the other three enjoyment items. In the study by[53] the items also had lowest correlation with the other items. The factor analysis with principal axis factorization yielded one factor explaining $60 \%$ of variance (eigenvalues $=1.8$ ).

Having determined the factor structure of the Kiswahili version of the measures, we then examined the gender differences in goal orientation, and cognitive (purpose of PE) and affective (satisfaction and enjoyment) outcomes of participation in PE classes in secondary schools in Tanzania.

\subsection{Gender Differences in Cognitive and Affective Variables in PE}

A one way Multivariate Analysis of Variance
(MANOVA)was conducted to examine gender differences on the study variables. The scale means were calculated (see table 1) and a significance gender main effect emerged over the scale means, Wilk`s Lambda.854, F $(11,388)=6.03$, p $<.001)$ indicating there were gender differences between males and females across the study variables. The multivariate eta squared based on Wilk's Lambda $=.15$ indicating that $15 \%$ of the multivariate variance is associated with gender factor. Table 1 contains means and standard deviation on the study variables for males and females.

The follow up univariate analysis of variance indicated that males were higher thanfemales in ego orientation $\mathrm{F}$ $(1,398)=6.73, p<.05$ and believed that social status was a more important purpose of PE than females. Furthermore, males believed that enhanced lifetime health skills $\mathrm{F}(1,398)$ $=12.59, \mathrm{p}<.001)$ to be more important purpose of PE than did female students. Furthermore, the analysis indicated that females perceived social responsibility to be more important purpose of $P E$ than did males $F(1,398)=10.78 p<01$. This was consistent with previous research [see 43,68, 51, 47, 69]. However, there were no gender differences in enjoyment and satisfaction during participation in PE. Thus, while there were consistent differences between males and females in cognitive outcomes, there were no gender differences in affective outcomes of participation PE.

Table 1. Means and standard deviations for variables under study by gender.

\begin{tabular}{|c|c|c|c|c|c|c|c|}
\hline & & \multicolumn{2}{|c|}{ Males } & & \multicolumn{2}{|c|}{ Females } & \multirow[b]{2}{*}{ F $(1,398)$} \\
\hline & & $\mathbf{M}$ & SD & & M & SD & \\
\hline Task orientation & 221 & 4.16 & $(.58)$ & 179 & 4.06 & $(.63)$ & \\
\hline Ego orientation & & 3.69 & $(.88)$ & & 3.49 & $(.76)^{*}$ & \\
\hline Status & & 3.56 & $(.96)$ & & 3.40 & $(1.03)^{* *}$ & \\
\hline Social responsibility & & 3.72 & $(.96)$ & & 4.00 & $(.73)^{* *}$ & \\
\hline Satisfaction with PE & & 4.15 & $(.59)$ & & 4.19 & $(.65)$ & \\
\hline Enjoyment in PE & & 4.43 & $(.60)$ & & 4.39 & $(.59)$ & \\
\hline
\end{tabular}

$* \mathrm{p}<.05 * * \mathrm{p}<.01$

To further examine the gender differences canonical correlations analyses were conducted. Because of the large number of observed gender differences in goal perspectives and cognitive and affective variables and the correlations among these three sets of variables separate canonical analyses were conducted for male and females. As expected there were clear gender differences in variables under study and the results showing standardized canonical coefficients for the significant functions for male and females are shown in table 2 .

Two significant gender main effect functions emerged with both male and females with overall Wilks' Lambda $=.674, \mathrm{~F}$ $(18,420)=5.083, \mathrm{p}<.001$ and $=.580, \mathrm{~F}(18,336)=5.844, \mathrm{p}<$ 001 for males and females respectively. The canonical correlations between the two linear combinations (criterion and predictor set of variables)was $=.523$ and .269 for males for function 1 and 2 respectively, and. 533 and.438 for females for function 1 and 2 respectively. Thus, the analysis indicates that there was a clear gender differences and the canonical coefficients indicate the contributions of variables to the multivariate relationship between the variable sets. To be considered significant, dependent variables must load at least 0.30 on any one function [70]. Because of the interesting gender differences the analyses and findings are presented for males and females separately.

\section{Males}

Males in the first function reflected high loading in the task and ego goal orientation. This high task/high ego orientation was related positively with social status, social responsibility, and lifetime health purpose of PE. These male students experienced high satisfaction and enjoyment during PE. 
Table 2. Canonical loadings: Goal orientation cognitive and affective variables for males and females.

\begin{tabular}{lllll}
\hline & Function 1 & \multicolumn{2}{l}{ Function 2 } \\
\cline { 2 - 5 } & Males & Females & Male & Female \\
\hline Goal orientation & & & & .561 \\
Task & .928 & .828 & -.372 & .944 \\
Ego & .405 & -.330 & .915 & .796 \\
Purpose of PE & & & & .403 \\
Status & .562 & .163 & .478 & .523 \\
Social responsibility & .481 & .721 & -.242 & .286 \\
Lifetime health & .636 & .607 & -.482 & .220 \\
Satisfaction & .616 & .474 & .050 & .101 \\
Enjoyment & .497 & .608 & & \\
\hline
\end{tabular}

Males in the second function showed high loading in ego orientation. This strong ego orientation related positively with social status while negatively related to lifetime health skills. There was no association with satisfaction and enjoyment in this function.

Females

On the other hand, females on the first function reflected high loading in task orientation. The predominantly task orientation was positively related to social responsibility and lifetime health skills and the high task females enjoyed and were satisfied with participation in PE. Furthermore, females on the second function reflected high task and ego orientation. These high task high ego females were related positively to social status, social responsibility, and lifetime health purpose of PE and were not associated with satisfaction and enjoyment during PE.

\section{Discussion}

\subsection{Validity and Reliability of the Instruments}

The present study examined the gender differences in goal orientation, cognitive and affective outcomes of participation in PE within Tanzanian context. The present study being conducted with PE students in cross-cultural context, we examined the factor structure of the questionnaire. The use of questionnaires namely, perception of success, purpose of PE, satisfaction and enjoyment when translated into Kiswahili was supported by the psychometric analyses in this study. Thus, the scales have been validated in Kiswahili context and confirmed that PE students were able to respond to the questionnaire.

In the result section the factor structure of the POSQ were presented revealing conceptually coherent factors thus, supporting goal theory. Results from factor analysis of the purpose of PE scale revealed that feeling important in front of people, getting recognition for winning, getting chance to be recognized as talented and getting status and opportunity to feel important, was the major purpose of participating in $\mathrm{PE}$ andloaded in the same factor (social status).

Furthermore, the results revealed that teaching to follow rules, respect authority, be socially responsible, cooperate, and develop socially desirable conduct was the purpose of participating in PE and loaded in the same factor (socially responsibility). The reason that these items loaded together is obvious, cooperating, and taking responsibility in physical activity is a more productive way towards mastery of skills important for health and social conduct. Lastly, results showed that views about increased control over one's body, developed increased awareness about health and encourage lifetime desire for regular participation in physical activities loaded in the same factor (lifetime health).

The present study being conducted with PE students in cross-cultural context, we examined the factor structure of the satisfaction scale. The factor analysis revealed one factor solution consistent with previous studies [44]. Thus, the fiveitem satisfaction scale was used in the current study and as expected the PE students produced results in the PE context as they would have produced if they had been tested in sport specific context.

Although enjoyment is theoretically complicated construct, the high correlation between the enjoyment scale items provided evidence that PE students perceived the items in similar way. One item "I have fun" was dropped due to low correlation with the other three items. More work is needed to reword this item in the future. Thus, the three items was used to measure the construct positive affect according to how enjoyment was defined in this study. Hence the scale wasprofitably used with Tanzanian PE students.

Because North America and Europe in one side and Africa on the other side have certain differences in socio-economic, political and cultural aspects, scales developed for pedagogical context in one are not automatically applicable in the other. In addition, translation is also generally problematic because the precise meaning of item is often culture bound. However, in the present study, the translation process was successful judging from the fact that the scales structures were consistent with the original scales in English and allowed conclusions to be made from relations between theoretical concepts. Therefore, within cross-cultural context the validity of the measures is confirmed. Having determined structure of the Kiswahili version of the measures, we then determined the gender differences in cognitive and affective outcomes of participation in PE within the achievement goal approach. 


\subsection{Gender Differences}

The main purpose of the present study was to examine gender differences in physical education in Tanzania. Specifically we examined gender differences in goal orientation, cognitive and affective outcome variables during participation in PE. As hypothesized and based on assumptions rooted in socialization theory [71], role stereotyping theories [72] and previous work of [51] and [47], the gender differences emerged in the variables under studyand continued to relate to variations in goal orientation(see table1).

Consistent with previous studies [44, 43, 68] in the present study males were higher in ego orientation than females. Thus, males were more oriented towards competitive success and demonstrating superiority over others in the form of winning than females. Research on goal perspective in sport has yielded results showing that males are more likely to be ego oriented and more competitive oriented than females because males tend to focus on winning and demonstrating ability in competitive context than females [73,43]. In contrast female athletes appear to be more task oriented than male athletes in several studies conducted in PE and sport context [43]. This finding is not surprising if we consider males have been oriented to equate success with winning [74]. Previous findings support that participants in coeducational PE school are usually high in ego orientation [e.g., 47].

Given the context of PE classes in Tanzania, this could be anticipated. In PE classes these females are exposed into coeducational PE classes with males and there is scarcity of resources for PE such as playing grounds and sports equipment and facilities. In this context there is"hidden atmosphere of struggle for survival" which elicit comparisons elements. In this environment where often one sport team is formed for the whole school and each one want to be in the team it is not easy to focus on improvement, mastery and trying hard without being concerned about one's better position than others in order to play in the only team available and be cheered by the whole school. It is also evident that there is limited sports equipment such as balls and often the whole class might have single ball for a particular ball game such as soccer, basketball, netball orvolleyball. Thus, there is element of wanting to outperform others in order to be selected to play the only ball available.

Furthermore, strong gender differences emerged in the perceived purpose of $\mathrm{PE}$, which is congruent with literature on sport attitude and values that males are higher in aggressive tendencies and lower in sportsmanship [see 43]. Specifically, females perceived PE as a context that promote cooperation, teach loyalty, desirable social conduct, respecting rules and authority and be social responsible more than males did. Thus, the present findingsindicating female perceiving purpose of $\mathrm{PE}$ as to promote co-operation, loyalty and desirable conduct and be responsible than males did and males scoring higher in lifetime health skills is congruent with other studies. Males, by contrastwere higher in perceiving that the major purpose of participation in PE was to get chance to be recognized as talented, for winning at all costs and a means to get greater social status. Several studies (e.g., [75] have suggested that adolescent males are more likely to pursue status in the context of physical activities that females. With Greek males it was found that they were more likely to believe that PE should help them increase their social economic status than females even after the differences in ego orientation has been adjusted [49].

Moreover, males were higher in considering that PE should enhance increased awareness of health and stimulate lifetime participation in physical activity than females. Nevertheless, the results which suggest that males were higher in ego orientation and also higher in awareness in lifetime health skills are somewhat surprising given other research showed that males high in ego were lower in life time health skills [44]. This may be due to existing gender stereotyping in Tanzania where males are perceived to engage in activities requiring muscular strength and fitness. Hence concern about health skills become important to them. The fear of females becoming masculine in appearance damaging the reproductive system (menstrual difficulties, pregnancy complications and exposing the body by wearing sport attire [76] can explain why females in this study scored lower in believing that increased awareness about health skills and stimulating lifetime participation in physical activity was the purpose of involvement in PE. Furthermore, the finding indicating females scoring higher than did males on social responsibility sub-scale is consistent with previous research [47] but also reflect the exiting culturally based gender roles in the Tanzanian society.

Several studies have reported gender differences in children's beliefs about their own competence in various physical activities and sport activities. Generally studies show that boys consistently report higher perception of their overall physical competence and that boys are more positive than girls about their ability in most traditional sport activities [77, 24, 78]. On the other hand research indicates that sex related movement tasks can reveal gender differences in ability perceptions, and for example it was found that males displayed more confidence on masculine typed tasks and females more confidence on feminine typed tasks [26, 27]. Furthermore, research indicate that overall young males value sport activities more than females do and some believe that females as a whole do not have the natural ability to be successful in physical education [24]. Nevertheless, evidence suggests however that females might not display lack of confidence in all activities and all situations related to achievement tasks [25].

Physical education in many societies is known to be the most gender segregated subjects in school curriculum [79]). Physical education in secondary schools in Tanzania for example is known to have a long tradition of being biased against girls. Thus, for example while male and female students within the same school have been receiving common lessons in subjects such as science, history mathematics and Kiswahili; they have being traditionally being taught $\mathrm{PE}$ aspects together but during 
their free time they characteristically take part in different types of physical activity and played different games [10]. Typically within Tanzanian school context, team sports such as football, and basketball are considered more masculine and sports such as netball, volleyball and physical activities such asgymnastics and dance more feminine $[18,80]$. A daily observation in Tanzanian society support the notion that women are more seen in caregiver roles such as nurse, early childhood teachers, childcares, midwives, social workers, and bar attendantsand because these roles would seem to require behavior that are communal in order to be successful and therefore females occupying these roles are assumed to be high in communal qualities. The fact that men are seen in roles perceived as requiring strength and work requiring power leads to young male students perceiving to be high in dimensions related to lifetime health and masculine. This self observation support the highly stereotyped assumptions for men expressing masculine qualities reflecting assertions and desire characterized as "agentic" whereas female expresses qualities reflecting concerns for others characterized as "communal" [72].

Gender stereotypes are cognitive structures that contain the organized set of beliefs an individual holds concerning the supposedly reliable differences between males and females. Stereotypes beliefs often play crucial role in directing interpersonal interactions. Thus, the findings in the present study where females scored significantly higher in social responsibility where females are more likely than men to follow rules, respect authority, be socially responsible, cooperate and develop desirable social conductare consistent with culturally based gender stereotypes in Tanzania. Likewise as males are seen in role requiring strength and masculine it is consistent that male students in secondary school in Tanzania scored significantly higher in desire for lifetime health skills.

\section{Conclusion}

Results from the current study indicate that for TanzanianPE students gender differences have substantial influence on individual's responses in PE. Gender was found to influence the socialization process in terms of achievement goal orientation and hence sheddingextra lights on the goal profile analysis. Thus, the findings suggest that in PE classes (where often males and females participate together), PE teachers should enhance task involvement during PE classes. Thus, if we want our PE students (both males and females) to endorse pro-social purpose of participation in $\mathrm{PE}$ and be satisfied and enjoy participation PE educators andPE teachers in Tanzania should teach students to try their best, cooperate, obey rules, respect authority, increase awareness about healthand encourage lifetime desire to participate in physical activity. Given that high task involvement conducive for positive responses from both males and females PE teacher's practices within Tanzania context designed to provide equal participation from both males and females should be based on inducing high task involvement to PE students. A major goal of educational reforms effort today is to identify ways that PE teacher can help students perceive purpose of PE as to contribute to young people's development, social responsibility, life time health, feeling of competence and thus increase their motivation [13, 19]. Conclusively, the findings in this study support such goal and add further validity to Nicholls argument regarding the relationship between individuals' goals and world- views about the purpose of activity in cross-cultural contexts [30].

Given the gender differences observed in this study and the existing gender stereotypes in Tanzanian society, clearly there is need for further research especially the contribution of all possible orthogonal achievement goal profiles on individual's psychological outcomes to involvement in PE. Nevertheless, it is current trend now that female in Tanzania are currently engaging in agentic roles and males performing some of the traditionally communal roles and thus disrupts the pattern of social roles and redistributing men and women in varying roles. For example, more and more women currently are engaged on nontraditional sport such as soccer, rugby, boxing, taekwondo and weight lifting. Future study should examine the effect of this trend in terms of gender differences in PE and sport.

\section{References}

[1] Mhando, S. (2015). Physical education and sport curriculum at teachers colleges in Tanzania: Appraisal of its implementation and development in Tanzania. Journal of Tourism Hospitality and Sports, 8, 1-12.

[2] Ministry of Education and Culture (MoEC) (2005). Physical Education Syllabus for Secondary Schools. Dar es Salaam: United Republic of Tanzania.

[3] Mziray, S. \&Kitta, S. (1996). The role and current position of Physical Education in Primary education in Tanzania. Papers in Education and Development, 17, 65-75.

[4] MoEC (1995). Education and Training Policy. Dar es Salaam: United Republic of Tanzania.

[5] Ministry of Education and Vocational Training ([MoEVT] (2009). Summary of Teachers training at certificate level for primary education. Haiba na Michezo, Dar es Salaam, United Republic of Tanzania.

[6] Bukuku, A. (2017). Assessment on implementation of teaching "HaibanaMichezo" in public primary schools in Ileje Tanzania. Unpublished masters thesis, University of Dar es Salaam, Tanzania.

[7] Bankobeza, A. (2015). The implementation of 'Haiba na Michezo'in Public Primary schools in Kinondoni Municipality in Dar es Salaam region. Unpublished masters thesis, University of Dar es Salaam:Tanzania.

[8] Simbo, U. (2014). Contributions of PE and sports to moral development among secondary students. Unpublished master's dissertation, University of Dar es Salaam.

[9] Sangawe, E. (2015). Sport talent identification and development in primary schools in Tanzania. Unpublished master's dissertation, University of Dar es Salaam, Tanzania.

[10] Mwasi, S. (2012). Haiba na Michezo sylabus in Tanzana:An assessement of the implementation. Dar es Salaam: Unpublished master thesis, University of Dar es Salaam, Tanzania. 
[11] Salum, S. S. (2015). Secondary schools Students' and teachers' attitude towards physical education inTanzania. Unpublished masters thesis, University of Dar es Salaam, Tanzania.

[12] Robert, A. (2014). The Contribution of sports Sponsorship to development of sports in educational Institutions in Tanzania. Unpublished masters thesis, University of Dar es Salaam, Tanzania.

[13] Maro, C. (2011). The Purpose of Physical Education as Perceived by PE students: The Goal orientation approach. Papers in Education and Development, 30, 154-178.

[14] Houlihan, B., \& Green, M. (2006). The changing status of school sport and physical education: explaining policy change. Sport, Education and Society, 11, (1), 73-92.

[15] Azzah, F. (2010, November 18th). "Sports in schools permitted, head of schools ordered". Mwananchi Daily Newspaper, pp. 23.

[16] Shehu, J., Akpata, D., Ogundare, O., Mziray, S. \&Kirimbai, R. (2003). Tanzanian school girls, sport and patriarchal logic: Preliminary data from an exploratory study. Papers in Education and Development, 23, 86-109.

[17] Jewett, A. (1987). The Purpose process curriculum framework. Journal of Teaching in Physical Education, 6, 195-226.

[18] Massao, P. (2001). Women in Sport. Feminist Analysis of Sport Development Policy of Tanzania.: Unpublished masters thesis, Norwegian University of Sport Sciences, Oslo, Norway.

[19] Kretschmann, R. (2014). The Purpose of physical education and their practical implications. Sport SPA, 11 (1), 25-28.

[20] Ennis, C. (1985). Purpose and concept in an existing physical education curriculum. Research Quarterly for Exercise and Sport, 56, 323-333.

[21] Ennis, C. (1994). Urban secondary teachers value orientations: Delineating curricular goals for social responsibilities. Journal of Teaching in Physical Education, 13, 163-179.

[22] Papaioannou, A. (1990). Goal Perspectives, Motives for Participation, and Purpose of Physical Education lessons in Greece, as Perceived by 14 and 17 year old Pupils. Unpublished master's thesis, University of Manchester, England.

[23] Lander, L. \& Chapman, P. (1987). The likeability and utility dimensions of the purpose elements. Journal of Teaching in Physical Education, 6, 234-242.

[24] Lee, A. M., Fredenburg, K., Belcher, D., \& Cleveland, N. (1999). Gender differences in children's conceptions of competence and motivation in physical education. Sport Education and Society, 4, (2), 161-174.

[25] Lenney, E. (1977). Women's self-confidence in achievement settings. Psychological Bulletin, 84(1), 1-13.

[26] Clifton, R. T. \& Gill, D. L. (1994). Gender differences in selfconfidence on a feminine-typed task. Journal of Sport \& Exercise Psychology, 16, 150-162.

[27] Lirg, D. (1991). Gender differences in self-confidence in physical activity. A meta-analysis of recent studies. Journal of Sport and Exercise Psychology, 13, (2), 294-310.

[28] Atkinson, J. W. (1964). An Introduction to motivation.
Princeton: IN, Van Nostrand.

[29] Bandura, A. (1989). Human agency in social cognitive theory, American Psychologist, 44, 1175-1184.

[30] Nicholls, J. (1989). The competitive ethos and democratic education. Cambridge, MA:Harvard University Press.

[31] Maro, C. N., \& Roberst, G. (2012). Combating HIV/AIDS in Sub-Saharan Africa:Effect of Introducing a Mastery Motivational Climate in a Community -Based Programme. Applied Psychology:An international Review, 6 (4), 699-722.

[32] Roberts, G. C. (2001). Understanding the dynamics of motivation in physical activity: The influence of achievement goals on motivational processes. In G. C. Roberts (Ed.), Advances in Motivation in Sport and Exercise (pp. 1-50). Champaign IL: Human Kinetics.

[33] Deci, E. L. \& Ryan, R. M. (1985). Intrinsic motivation and self-determination in human behavior. London: Plenum.

[34] Deci, E. L. \& Ryan, R. M. (2002). Handbook of self determination research. Rochester, NY: University of Rochester Press.

[35] Maehr, M. \&Braskamp L. (1986). The motivational factor. A theory of personal investment. Lexington, MA: Lexington Books.

[36] Duda, J. L. (1993). Goals: A social cognitive approach to the study of achievement motivation in sport. In R. N. Singer, M. Murphey, \& L. K. Tennant (Eds.), Handbook of research on sport psychology (pp. 421-436). New York: Macmillan.

[37] Duda, J. L. (1994). Fostering active living for children and youth: The motivational significance of goal orientations in sport. Champaign: Human Kinetics.

[38] Ames, C. (1984). Competitive, cooperative, and individualistic goal structures: A cognitive motivational analysis. In R. Ames \& C. Ames (Eds.), Research on motivation in education: Student motivation (pp 177-208). New York: Academic Press.

[39] Nicholls, J. G. (1984). Achievement motivation: Conception of ability, subjective experience, task choice, and performance. Psychological Review, 91, 328-346.

[40] Duda, J. L. (1992). Motivation in sport settings: A Goal Perspective Approach. In G. C. Roberts (Ed.), Motivation in Sport and Exercise (pp. 57-91). Champaign IL: Human Kinetics.

[41] Dweck, C. \& Leggett, E. (1988). A social cognitive approach to motivation and personality. Psychological Review, 95, 256273.

[42] Nicholls J., Patashnick, M., \& Nolen, S. B. (1985). Adolescents' theory of education. Journal of Educational Psychology, 77, 683-692.

[43] Duda, J. (1989). The relationship between task and ego orientation and the perceived purpose of sport among male and female high school athletes. Journal of Sport and Exercise Psychology, 11, 318-335.

[44] Roberts, G., Hall, H., Jackson, S., Kimiecik, J., \&Tonymon, P. (1995). Implicit theories of achievement and the sport experience: Effect of goal orientations on achievement strategies and perspectives. Perceptual and motor skills. 81, 219-224. 
[45] Papaioannou, A. (1992). Students' motivation in physical education classes. Unpublished doctoral dissertation, University of Manchester, England.

[46] Papaioannou, A. (1994). The development of a questionnaire to measure to achievement orientation in physical education. Research Quarterly for Physical Education and Sport, 65, 11-20.

[47] Papaioannou, A. and Mcdonald, A. (1993). Goal perspectives and purpose of physical education as perceived by Greek adolescents. Physical Education Review, 16, (1), 41-48.

[48] Walling, M. \&Duda, J. (1995). Goals and their association with beliefs about success and perception of the purpose of physical education. Journal of Teaching Physical Education, 14, (2), 140-156.

[49] Papaioannou, A. (1998). Student's perceptions of physical education class environment for boys and girls in Greece and perceived motivational climate. Research Quarterly for Exercise and Sport, 69,267-275.

[50] Roberts, G., Tressure, D., \&Kavussanu, M. (1997). Motivation in physical activity context: achievement goal perspective. In M. Maehr \& P. Pintrich (Ed.), Advances in the motivation and achievement (pp.413-447). New York: JAI press.

[51] Louchbaum, M., \& Roberts, G. (1993). Goal orientation and perceptions of sport experience. Journal of Sport and Exercise Psychology, 15,160-171.

[52] Roberts, G. \&Ommundsen, Y. (1996). The effect of goal orientations on achievement beliefs and strategies in team sport. Scandinavian Journal of Medicine Science and Sport, 6.46-56.

[53] Liukkonen, J. (1998). Enjoyment in youth sports. A goal perspective approach. Unpublished doctoral thesis, University of Jyvaskyla, Finland.

[54] Scanlan, T. \& Simons, J. (1992). The construction of sport enjoyment. In G. C. Roberts (Ed.), Motivation in sport and exercise (199-215). Champaign, IL: Human Kinetics.

[55] Deci, E. \& Ryan, R. (1980). The empirical exploration of intrinsic motivational process. In L. Berkowitz (Ed.), Advances in experimental social psychology, (pp39-80). New York: Academic press.

[56] Wankel, L. (1997). "Strawspersons" selective reporting and inconsistent logic: A response to Kimeicik and Harris's analysis of enjoyment. Journal of Sport and Exercise Psychology, 15, 98-109.

[57] Vallerand, R., Deci, E., \& Ryan, R. (1988). Intrinsic motivation in sport. In K. Pandolf (Ed.), Exercise and sport science reviews (pp.389-425), New York: MacMillan.

[58] Gill, D., Gross, J., \& Huddleton, S. (1983). Participation motivation in youth sports. International Journal of Sport Psychology, 14, 1-14.

[59] Duda, J. Chi, L., Newton, M., Walling, M., \&Catley, D. (1995). Task and ego orientations and intrinsic motivation in sport. International Journal of Sport Psychology, 26, 40-63.

[60] Roberts, Treasure \&Kavussanu, (1996). The orthogonality of achievement goals. Beliefs about success and satisfaction in sport. The sport psychologist, 10, 398-408.

[61] Kavussanu, M., \& Roberts, G. (1996). Motivation in physical activity context: The relationship of perceived motivational climate to intrinsic motivation and self-efficacy. Journal of Sport and Exercise Psychology, 18, 264-280.

[62] Jackson S., \& Roberts, G. (1992). Positive performance state of athletes: Towards a conceptual understanding of peak performance. The Sport Psychologist, 6, 156-171.

[63] Vygotsky, L. S. (1978). Mind in society: The development of higher psychological processes Cambridge, Mass.: Harvard University Press.

[64] Telama, R., Laakso, L., \& Yang, X. (1994). Physical activity and participation of young people in Finland. Scandinavian Journal of Medicine and Science in Sports, 4, 65-74.

[65] Roberts, G., \& Balague, G. (1991 sept.). The development and validation of the perception of success questionnaire. Paper presented at FEPSAC congress, Cologne, Germany.

[66] Ommundsen, Y., Roberts, G., Kavusanu, S. (1998). Perceived motivational climate and cognitive and affective correlates among norwegian athletes. Journal of Sports Sciences, 16, 153-164.

[67] Scanlan, T., Carpenter, P., Schmidt, D., Simons, J., \&Keeler, B. (1993). An introduction to the sport commitment model. Journal of Sport and Exercise psychology, 15, 1-15

[68] Gill, D. (1988). Gender differences in competitive orientation and sport participation. International Journal of Sport Psychology, 19, 145-159.

[69] Treasure, D. \& Roberts, G. (1994). Cognitive and affective concomitants of task and ego goal orientations during the middle school years. Journal of sport and exercise psychology, 16, (1), 15-28.

[70] Tabachnick, B. \&Fidell, L. (2007). Using multivariate statistics $\left(6^{\text {th }}\right.$ ed.) Boston: Pearson/Allyn and Bacon.

[71] Loy, J., Mcpherson, B., \& Kenyon,, G. (1978). Sport and social systems. Reading Mass: Addison-Wesley Pub. Co.

[72] Eagly, A. \& Steffen, V. (1984). Gender stereotypes stem from the distribution of men and women into social roles. Journal of Personality and Social Psychology, 46, 735-754.

[73] White, S. \&Duda, J. (1994). The relationship of gender, level of sport involvement and participation motivation to task and ego orientation. International Journal of Sport Psychology, 25, 418.

[74] Coakley, J. (2009). Sport in Society: Issues and controversies. $\left(12^{\text {th }}\right.$ ed.). London: Mcgraw-Hill.

[75] Thirer, J. \& Wright, S. (1985). Sport and social status of adolescent's males and females. Sociology of Sport Journal, 2, 164-171.

[76] Adedeji, J. A. (1984). Women's sport in developing countries. International council of Sports Science and physical education, 36-43.

[77] Eccles, J. S., Wigfield, A., Flanagan, G., Miller, C., Reuman, D., \& Yee, D. (1989). Self concept, domain values, and selfesteem: Relations and changes at early adolescence. Journal of Personality, 57, 283-310.

[78] Marsh H. \& Peart, N. (1988). Competitive and Coperative Physical Fitness training programs for girls: Effects on physical fitness and multidimensinal self-handicaping strategies. Journal of Sport and Exercise Psychology, 10, 390-407. 
[79] Waddington, I., Malcolm, D., \& Cobb. J. (1998). Gender stereotyping and physical education, European Physical Education Review, 4, 34-64.
[80] Massao, P., \& Fasting, K. (2003). Women and Sport in Tanzania. In I. Harmon-Tews, \& G. Pfister, Sport and Women:Social Issues in International Perspectives (pp. 118130). London: Routle dge \&ISCPES. 